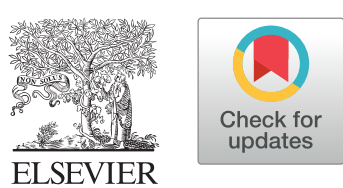

\title{
Review
}

\section{Racism and Cardiology: A Global Call to Action}

\author{
Shrilla Banerjee, MD, FRCP, ${ }^{a}$ F. Aaysha Cader, MD, MRCP, ${ }^{b}$ \\ Martha Gulati, MD, MS, FACC, FAHA, FASPC, FESC, ${ }^{\mathrm{c}}$ and Quinn Capers, IV, MD, FACC ${ }^{\mathrm{d}}$ \\ ${ }^{a}$ Department of Cardiology, Surrey and Sussex Healthcare NHS Trust, Redhill, United Kingdom \\ ${ }^{b}$ Department of Cardiology, Ibrahim Cardiac Hospital \& Research Institute, Dhaka, Bangladesh \\ ${ }^{c}$ Division of Cardiology, University of Arizona, Phoenix, Arizona, USA \\ ${ }^{d}$ Division of Cardiology, University of Texas Southwestern, Dallas, Texas, USA
}

\begin{abstract}
Racism and racial bias influence the lives and cardiovascular health of minority individuals. The fact that minority groups tend to have a higher burden of cardiovascular disease risk factors is often a result of racist policies that restrict opportunities to live in healthy neighbourhoods and have access to high-quality education and healthcare. The fact that minorities tend to have the worst outcomes when cardiovascular disease develops is often a result of institutional or individual racial bias encountered when they interact with the healthcare system. In this review, we discuss bias, discrimination, and structural racism from the viewpoints of cardiologists in Canada, the United Kingdom, and the US, and how racial bias impacts cardiovascular care. Finally, we discuss proposals to mitigate the impact of racism in our specialty.
\end{abstract}

Black, White, Indigenous, Asian, South Asian-these are some of the derivations used to describe race. Race is a social construct that describes a group of people that appear the same but genetically may be very different. Your race is the group of people to whom you bear most resemblance-your phenotypic appearance to the rest of the world. However, race is an umbrella term that suggests similarity when in fact the group may be very heterogeneous but just appear the same superficially. For instance, the term Black in Canada, the United Kingdom (UK,) or the US may describe not only a recent migrant from Ethiopia or Somalia but also a descendent of Black slaves whose relatives have lived for generations

Received for publication June 29, 2021. Accepted September 13, 2021.

Ethics Statement: The research mentioned in this article has adhered to relevant ethical guidelines and standards.

Corresponding author: Dr Shrilla Banerjee, Department of Cardiology, Surrey and Sussex Healthcare NHS Trust, Redhill RH1 5RH, United Kingdom.

E-mail: shrilla.banerjee@nhs.net

See page S170 for disclosure information.

\section{RÉSUMÉ}

Le racisme et la discrimination raciale influent sur la vie et la santé cardiovasculaire des membres des minorités. Le fait que les groupes minoritaires tendent à présenter plus de facteurs de risque de maladies cardiovasculaires est souvent le résultat de politiques racistes qui restreignent les possibilités de vivre dans des quartiers sains et d'avoir accès à une éducation et à des soins de santé de grande qualité. Le fait que les minorités tendent à afficher les pires résultats lorsqu'une maladie cardiovasculaire se manifeste est souvent le résultat d'une discrimination raciale systémique ou individuelle à l'œuvre dans leurs interactions avec le système de santé. Dans le présent article, nous traitons de la discrimination et du racisme structurel du point de vue de cardiologues du Canada, du Royaume-Uni et des États-Unis. Nous abordons également l'incidence de la discrimination raciale sur les soins cardiovasculaires. Enfin, nous proposons certaines mesures visant à atténuer l'effet du racisme dans notre spécialité.

in that particular country. Conversely, a person's ethnicity is determined by the genetic heritage that they receive from their forebearers. Race combines a group of people who may vary not only ethnically but also with other social determinants of health, including income, education, employment status, working life conditions, housing, food insecurity, early childhood development, social inclusion, and access to affordable healthcare. There is no biologic basis for race-based health disparities. Despite this, race predicts health outcomes. However, it is racism, and not race, that is the fundamental driver of these health inequities.

Essentially, racism is the belief that different races possess distinct characteristics, abilities, or qualities that distinguish them as inferior or superior to one another. There are 3 major forms of racism: explicit, implicit, and institutional, also known as structural.

Explicit racism is easily detectable and easy to condemn. Implicit racial bias is the unconscious association of positive or negative attributes with different racial groups. Unconscious or implicit bias can take many forms and includes bias based on gender, race, and other characteristics. Such bias is 
influenced by a person's environment, including friends, family, colleagues, and the beliefs drawn from stereotypes, the media, and the culture around that individual. ${ }^{2-5}$. The amygdala, part of the limbic cortex, is the driver of implicit bias. Although implicit biases occur outside of conscious awareness or control, they can influence behaviour and lead to discrimination. Reducing the effects of such bias can be facilitated by engaging the frontal cortex to allow recognition of one's bias, carefully -challenging oneself, and ultimately developing empathy and encouraging diversity. ${ }^{6}$

Structural racism results from years of policy-making that gives advantage to one racial group at the expense of another. This type of racism is more pervasive and often difficult to identify and define. ${ }^{7}$ Structural racism operates through mutually reinforcing systems that determine factors such as the following: the conduct of the criminal justice, healthcare, and educational systems; where people are allowed to live; the proximity of people's homes to clean air, water, healthy food, and green space; and access to high-quality hospitals. These factors have been suggested to have as great an impact on cardiovascular disease outcomes as traditional cardiovascular risk factors. ${ }^{8}$ Structural racism has been a significant cause of persisting health and healthcare disparities in Canada, ${ }^{7}$ the $\mathrm{UK}^{3,9}$ and the US. ${ }^{10,11}$ However, evidence indicates that interventions can impact structural racism. For instance, in the US in the 1960s-1970s, ${ }^{12}$ civil rights policies narrowed the economic gap between Blacks and Whites, reduced some health inequities, and resulted in improved living conditions and socioeconomic opportunities, although significant and still troubling inequity persists. Cardiologists must be aware that our patients can be impacted by the effects of all levels of racism. In this review, we discuss bias, discrimination, and structural racism from the viewpoints of cardiologists in Canada, the UK, and the US, how racial bias impacts cardiovascular care, and proposals to mitigate the impact of racism in our specialty.

\section{Racism, Health, and Heart Disease}

\section{Racism, health, and heart disease in the UK}

In a 1999 report investigating the police response to the racially motivated murder of a Black teenager in the UK, Sir William Macpherson coined the term "institutional racism" and concluded that the metropolitan police serving London, as an institution, were racist, and that this institutional or structural racism extended to the British Civil Service, the local government, systems of education, and the National Health Service. ${ }^{13}$ In the nearly 22 years since that report, ethnic minorities still live in socially disadvantaged and densely populated neighbourhoods, and experience greater social deprivation than the ethnic majority. ${ }^{14}$ These factors have a negative impact on the health of minority ethnic and disadvantaged communities. For instance, the recent coronavirus disease 2019 (COVID-19) pandemic has had a disparate impact on people of colour within the UK, with infection and death rates much higher than is commensurate with their relative representation in the population. ${ }^{15}$ Despite the National Health Service providing universal healthcare, the pandemic has unmasked the inequities in the lack of health promotion and adequate healthcare in less-affluent, immigrant, and ethnic minority populations. ${ }^{16}$ To reduce racial disparities in cardiac care in the UK, it is imperative to address national policies that sustain inequalities in healthcare, education, and housing, as well as physician and systemic biases.

\section{Racism, health, and heart disease in the US}

In the US, longstanding social policies have resulted in limited access to quality education and healthcare for people of colour. Since the first Africans were captured and forcibly transported to the US in 1619, structural racism has had an ongoing negative impact on the health of Black people. ${ }^{17}$ Such racism affects everything from the lack of resources to maintain healthy behaviours in minority neighbourhoods to the disparate treatment minorities receive when they engage with the healthcare system.

The mere perception that one is being discriminated against has been associated with a higher risk of high blood pressure, ${ }^{18}$ depression, ${ }^{19}$ and coronary artery stenoses ${ }^{20}$ in Black individuals. An analysis from the third National Health and Nutrition Examination Survey found an association between the higher mortality incidence among Blacks and the higher "allostatic load" (ie, wear and tear on the body resulting from stress) they experience. ${ }^{21}$ These factors could adversely impact the cardiovascular prognosis of Blacks in addition to that for Hispanics, Asians, and Native Americans in the US, even before they encounter the healthcare system. When racial bias awaits at the doctor's office or the hospital, the impact of racism on their health is compounded.

Although structural racism is clearly a contributor to the shortened life expectancy of Blacks and Hispanics in the US, individual racial bias on the part of physicians and health institutions cannot be excluded and must be explored. Racial disparities in care have been noted in Veteran's Affairs hospitals in the US, where fundamentally, access should be the same for all patients, ${ }^{22}$ and have been found to persist even after reforms such as mandated insurance for all, ${ }^{23}$ a response to the glaring and disproportionally high numbers of uninsured Black Americans. In an analysis of US data from 9 states between 2000 and 2005, after adjusting for demographics, comorbidities, and hospital clustering, Blacks and Hispanics with acute myocardial infarction were approximately $25 \%$ and $5 \%$ less likely to be treated with revascularisation, respectively, than Whites with similar insurance. ${ }^{10,24,25}$ Such data indicate that differences in insurance status do not fully explain racial disparities in care. The Affordability and Real-World Antiplatelet Treatment Effectiveness After Myocardial Infarction Study (ARTEMIS trial), ${ }^{26}$ which looked at the effect of copayment intervention on antiplatelet medication in 6135 post-acute coronary syndrome patients, found a slight improvement in the uptake of antiplatelets when barriers to copayment were removed, but no impact on the 1-year incidence of major adverse cardiac events. These studies suggest that there are other barriers to optimal care, beyond finances and insurance status, that contribute to race-based heath inequality. Reducing racial disparities in cardiovascular care in the US requires a multipronged approach, including policy changes in regard to housing segregation, healthcare access (ie, social determinants of health), and training of a diverse group of physicians and healthcare providers. Interventions, such as 
having a doctor of similar race, have been shown to result in better health uptake, in particular for Black patients. ${ }^{27}$

\section{Racism, health, and heart disease in Canada}

Recent reports, including Canada's Truth and Reconciliation Commission Report, published in 2015, state that the poor health statistics of the country's First Nations, Inuit, and Metis peoples are due in part to systemic racism and discrimination. ${ }^{25,10}$ This population has the highest cardiovascular disease burden in the nation, attributable in part to the effect of colonization and government policies that have resulted in lower socioeconomic status, lower-quality healthcare, less primary cardiovascular disease prevention, poor access to nutritional foods, and a shift away from traditional practices of Canada's First Nation people. ${ }^{28}$ The burden of cardiovascular risk factors is significantly higher in this group, as is the overall mortality rate. ${ }^{29,30}$

A reduction in these disparities and those suffered by other minority groups in Canada requires a national response to identify and close the gaps in healthcare between the majority White population and minority groups. The barriers to accessing healthcare include racism and aggression, disrespect, differential healthcare, discontinuity of language, and lack of cultural understanding of viewpoints or definitions of health. ${ }^{31}$ Factors necessary to reduce these disparities include required education of all students in healthcare, specifically those in medicine and nursing, on racial healthcare disparities, including Indigenous teachings and practices, with required skill-based training in intercultural competency, human rights, and antiracism. The challenge for the Canadian populace is to lessen or remove the barriers to health of the Indigenous Peoples, and in doing so, reduce the impact of systemic racism and the colonial past. This involves deep-rooted change and systemic dismantling of entrenched attitudes toward the First Nations peoples, and instead the nurturing of a culture of mutual respect, understanding, and trust. Healthcare policy must involve learning from Indigenous-led movements. ${ }^{31}$ Cardiologists must grasp the mantle and lead this change to help drive down the disparity in cardiovascular outcomes, to eventually create better healthcare outcomes and equity for Indigenous Peoples, and for all.

\section{Influence of Racism and Racial Bias in Cardiovascular Care}

\section{Racial disparities in automatic implantable cardioverter- defibrillator (AICD) implantation}

Epidemiologic studies suggest higher rates of cardiac arrest in Blacks and individuals from socioeconomically disadvantaged backgrounds. ${ }^{32,33}$ Black and Hispanic neighbourhoods also have lower rates of bystander cardiopulmonary resuscitation and automatic external defibrillator (AED) use. ${ }^{34,35}$ For most individuals who survive a cardiac arrest, treatment with implantation of an AICD is considered a class I indication. ${ }^{36}$ Studies documenting racial and gender disparities in the use of implantable defibrillators began to appear in the 1990 s, $^{37}$ and appeared as late as 2018. ${ }^{38}$ Numerous articles have shown that Blacks and women are less likely than White males to receive a defibrillator when one is indicated. Intersectionality may be additive; one study showed that Black women were least likely of all groups to receive a defibrillator when it was indicated. ${ }^{39}$

Thus, current evidence reveals that Blacks and Hispanics are more likely to suffer a first cardiac arrest, tend to reside in neighbourhoods where rescue with bystander cardiopulmonary resuscitation or automatic external defibrillators $s$ is less common, and, should they happen to survive a cardiac arrest, are less likely to subsequently receive AICDs. Unless systemic changes are enacted, Blacks, Hispanics, and other underserved groups will remain more likely to die of sudden cardiac arrest than other groups.

Authors have speculated on potential causes for race and sex disparities in AICD implantation, including patientprovider mistrust and differences in socioeconomic status, insurance levels, and health literacy. Some have suggested that rather than an underutilization in Blacks and women, the devices are overutilized in White males. ${ }^{40}$ Implicit physician bias has been implicated in the underutilization of other advanced therapies in Black patients ${ }^{41}$ and may contribute to disparities in defibrillator implantation.

\section{Racial bias and disparities in the care of acute coronary syndromes}

Disparities in care are particularly relevant in the management of the acute coronary syndromes (ACSs), with which time is of the essence. During the early era of reperfusion in the US, door-to-needle (thrombolytic therapy) and door-to-balloon times were significantly longer in Blacks compared to those for Hispanics and Whites. ${ }^{42}$ More recent studies reveal that Black patients with ACS have longer wait times in the emergency department ${ }^{43}$ and experience delays in coronary angiography and preferential use of bare metal vs drug-eluting stents. ${ }^{4,45}$

In the United Kingdom, South Asian patients with symptomatic coronary artery disease are less likely than White patients to be evaluated with coronary angiography and revascularisation and to be treated with the appropriate medications. $^{46,47}$ This disparity may be explained partly by the greater likelihood that they live in areas with relative social and economic deprivation. ${ }^{14}$ Previous studies have pointed out the differential care provided to Black, South Asian, and minority ethnic patients presenting with an acute myocardial infarction. In a recent study from the $\mathrm{UK}$, minority patients presenting with ACS during the COVID-19 pandemic had more pronounced delays in receiving reperfusion therapies, compared with Whites, were less likely to be evaluated with coronary angiography, and had higher in-hospital and 7-day mortality. ${ }^{48}$

In the US recently, the Montefiore ST-segment elevation myocardial infarct (STEMI) registry, in an evaluation of differences in management of 1208 STEMI patients, by age, sex, and race/minority group, revealed differences in the use of primary angioplasty in the elderly and African Americans that were not explained by severity of illness, suggesting that appropriate interventions and therapies may be withheld from those who may benefit most. ${ }^{49}$ These findings are not new: similar disparities in the provision of revascularisation, to stable angina patients, were reported from Duke University in 1997 , in a study of 12,402 patients undergoing angiography. Black patients with coronary disease were less likely than Whites to be treated with angioplasty, and were markedly less likely to undergo bypass surgery. ${ }^{50}$ This inequity could not be 


\section{IMPROVING EQUITY, INCLUSION \& DIVERSITY IN \\ CARDIOLOGY TO IMPROVE THE CARE OF ALL \\ CARDIOVASCULAR PATIENTS}

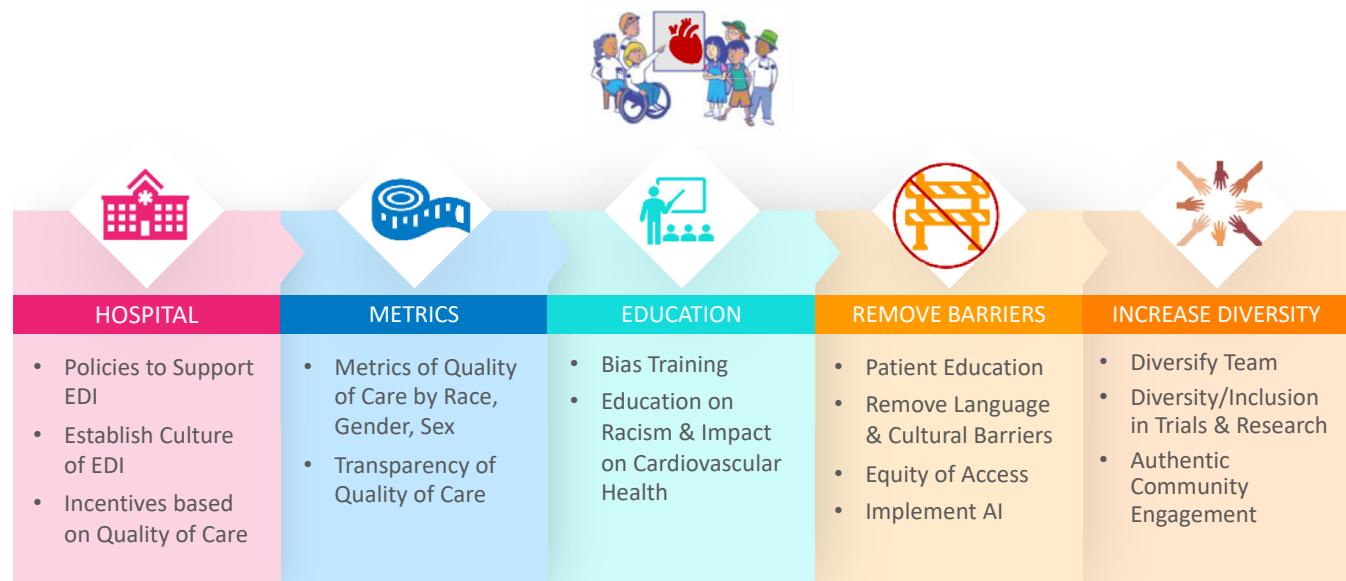

Figure 1. Schematic of strategies to reduce the impact of racism on cardiovascular care. Al, artificial intelligence; EDI, equity, diversity, inclusion.

explained by clinical factors or differential access to care. The underuse of prognostically important revascularisation procedures resulted in worse observed outcomes. Although both these studies were limited by including patients treated in just one institution, and hence were not reflective of national policy, the trends have been confirmed in other publications. $^{5}$

In Canada, a 2009 study of a multiracial group of patients with acute myocardial infarction found that among White, Chinese, South Asian, Southeast Asian, and First Nations individuals, Whites were significantly more likely to undergo angiography within 3 hours of presentation compared with all other groups. ${ }^{56}$

Thus, racial variation in the treatment of acute myocardial infarction is a global problem, with Black, Hispanic, Asian, Indigenous, and other minorities less likely than Whites to receive evidence-based care in several countries. The fact that this theme is consistent across national borders makes it less likely that the sole culprit is variation in national systems of healthcare financing and strongly suggests a role for race. However, this statement may be too simplistic: in registry data looking at outcomes of STEMI by age and sex in a lowincome population, it was found that younger patients (regardless of race) had a higher burden of risk factors, and in particular, those from socially disadvantaged backgrounds were more impacted by health disparity relating to STEMI. ${ }^{49}$ This finding correlates with data suggesting that race and ethnicity play a significant role in a patient's social determinants of health. A greater number of social determinants of health associated with a patient can predict a worse cardiovascular outcome. ${ }^{8}$

Yet, it is racism, not race, that is the primary driver of the social determinants of health. Racism drives the inequities in housing, income, and education, especially among communities of colour. Furthermore, racism is not just one of the social determinants - it is the underlying structural determinant that sets the stage for all the other social determinants.

\section{Racial disparities in structural heart disease interventions}

In the US, racial minorities with severe aortic stenosis are less likely than Whites to have surgical or transcatheter aortic valve replacement (TAVR), with White patients undergoing more than $90 \%$ of the valve replacement procedures in both the pre- and post-TAVR eras. ${ }^{57,58}$

The reasons for the lower utilization of TAVR among nonWhite patients are likely multifactorial, but they include a lower likelihood of being referred for any aortic valve repair (surgical or TAVR), ${ }^{59}$ lower socioeconomic status and access to care, ${ }^{60}$ patient mistrust, and lack of culturally competent communication on the part of physicians and providers. ${ }^{61}$

\section{Time to Intervene: Reducing the Impact of Racism and Racial Bias in Cardiovascular Care}

Reducing the impact of racism by mitigating individual implicit biases

We recommend that cardiologists and members of the cardiovascular care team make sincere efforts to mitigate their individual biases. Implicit biases or associations can be measured by the computer-based implicit association test (IAT), the results of which have been shown to predict discriminatory behaviour. ${ }^{3,4,62-64}$ The IAT appears to be a valid measure of unrecognised social beliefs, but it must be recognised that some limitations or concerns still remain. ${ }^{65-67}$ In particular, the relative nature of the measure and its subsequent impact on behaviour need further evaluation. Furthermore, there is an argument that implicit bias training may breed resentment and be counterproductive. ${ }^{65}$ However, it appears that the benefits and potential gains for behavioural research outweigh these concerns, and the IAT provides a much-needed measure with strong psychometric properties. ${ }^{67}$

Alarmingly, it has been shown that if physicians unknowingly hold negative or positive implicit biases about a patient 
under their care, the biases can influence clinical decisionmaking and interpersonal communication. A study in 2007 found that physicians with negative implicit biases about Black individuals were less likely to treat Black compared to White heart attack victims with life-saving thrombolytic drugs. ${ }^{68}$ In an analysis of doctor-patient interactions in the office setting, oncologists with implicit negative biases about Black people spent less time with their Black patients and displayed a verbally dominant tone during the office visit. ${ }^{69}$ In a more recent, vignette-based study using Black and White male patients, Breathett et al. found that heart failure specialists were more likely to consider a Black man to be at risk for nonadherence $^{41}$ The cardiologists were more likely to offer a White man heart transplantation; a Black man was more often referred for a left ventricular assist device, currently considered the inferior option of the two. Although the sobering news is that many physicians hold implicit negative biases about Blacks, and that this bias is pervasive, with nearly $70 \%$ of IAT takers demonstrating some degree of implicit association of a White face with "good" and a Black face with "bad" 2,70 mitigation of these biases is possible. Several studies have shown that educational interventions targeted at faculty members in science, technology, engineering, medicine, and mathematics departments can be successful at increasing awareness of and reducing biases. Positive outcomes range from a reduction in self-reported bias, to an increase in the diversity of students matriculating into medical school, and an increase in hiring women faculty in science departments. ${ }^{71-74}$

There is some evidence that just becoming aware of one's bias can help reduce it. ${ }^{3}$ Studies have shown that human behaviours are changeable and dependent on their environments. ${ }^{75,76}$ Recurring workshops or discussions to rehearse bias mitigation strategies can be undertaken as a team. We prefer a model in which clinical cases are presented and discussed, and workshop participants intentionally list items that could trigger biases (race, skin tone, gender, perceived religion, obesity, etc.) and then verbally "rehearse" researchproven bias-mitigation strategies. ${ }^{77}$ These discussions should be led by an experienced bias-mitigation workshop leader. Although data indicating that cardiovascular outcomes are improved by bias-mitigation training of healthcare teams are lacking, ${ }^{63,66,67}$ there is evidence that educating clinicians and healthcare workers in strategies to override racial and other biases may enhance the atmosphere of inclusion perceived by patients and colleagues alike, and enhance patient trust. ${ }^{78}$

\section{The promise of using artificial intelligence (AI) to reduce} the impact of racism

We recommend that the specialty of cardiology accelerate research into the use of $A I$ as a tool to reduce the impact of racial bias in medicine. AI has the potential to be implemented in numerous ways to reduce bias in cardiovascular care and allow for implementation of precision medicine. (Fig. 1). The potential for AI to remove the inequities in care is only possible if the AI algorithms have excluded biases and confounding factors. ${ }^{79}$

AI can be incorporated into electronic health record platforms using predictive modelling to prompt specific care approaches. An example of its utility is shown in Figure 1. AI has the potential to eliminate or reduce biases in cardiovascular care. An example of such AI has been demonstrated in STEMI care- a standardized approach reduced the disparities in care of women and improved outcomes when they presented with STEMI. ${ }^{80}$

Although the use of AI has the potential to improve cardiovascular outcomes by removing bias, it is no panacea for racism in medicine; the data entered into the AI systems must be clear of bias, and the clinicians supervising/overseeing the process must not contribute their bias to the algorithms. ${ }^{81}$

\section{Reducing the impact of racism by enhancing diversity in medicine and cardiology}

We recommend that cardiology accelerate efforts to recruit and matriculate underrepresented groups into medicine and cardiology. The lack of racial diversity in medicine and cardiology is a culmination of inadequate resources in public schools in minority neighbourhoods, a dearth of Black, Hispanic, First Nation, and Native American physicians to inspire minority children, the prohibitive costs of a college and medical education, and explicit and implicit biases by many "gatekeepers," from grade school to medical school. Race and sex biases that put women and minorities at a disadvantage for achieving a quality education have been well described and include biases during the high school years and earlier. ${ }^{82,83}$. In a world where $70 \%$ of IAT takers demonstrate an implicit association of White faces with "good" and Black faces with "bad," 76 the minority child who dreams of being a physician faces nearly 2 decades of obstacles. Because the lack of diversity in cardiology is one contributor to racial disparities in cardiac care, ${ }^{84}$ it deserves attention and should be addressed with urgency.

The argument for diversity in medicine is an easy one to make: (i) physicians from underrepresented or disadvantaged groups are more likely to locate their practices in and serve underserved communities ${ }^{85}$; (ii) black physicians are least likely of all physician groups to harbour negative implicit racial biases against other groups ${ }^{71}$; and (iii) minority patients are more likely to comply with recommendations from physicians that share their cultural background. ${ }^{27,86}$

Finally, another aspect of racism that is rarely discussed is the personal moral responsibility to speak up when witnessing racism and the effects of structural racism. We can no longer shrug our shoulders and turn away. We have a moral responsibility to speak out and fight for the overlooked and the forgotten in our society. We must use our privileged position, as healthcare professionals and educators, to improve the lives of our patients and colleagues. ${ }^{87-90}$

Ultimately, accomplishing major changes in the diversity of the medical workforce will require changes in public policy to dismantle the structural racism that traps many children in poverty and/or deprives them of access to high-quality education. However, the academic medicine and cardiology community can and must take active steps now. We recommend a tripartite approach to enhancing the diversity of the physician workforce. ${ }^{91}$ The first step is to reach out to the "deep pipeline" of minority children and girls, by exposing them to medicine and cardiology via hands-on learning sessions in simulation centres and visiting high school "career day" sessions. The second step is outreach to the "intermediate pipeline" of college and medical students and internal medicine residents by serving as mentors and allowing them to 
"shadow" when possible. It is important to provide mentors and role models from the minority groups, to overcome the common impact reflected in the phrase "You can't be what you can't see." The final step is to "de-bias" the selection stages; we recommend utilizing tools at the stage of selection of medical students, residents, and fellows, such as holistic review and a point-score system that prioritizes cultural competence, experience serving underserved populations, and likelihood of serving disadvantaged communities. ${ }^{70}$

In Canada, the push for diversity has begun. The University of Manitoba's medical school admissions committee detected that the privilege of being White and wealthy resulted in higher medical college admission test (MCAT) scores and more successful interviews. Subsequently, the dean for admissions convened a panel of experts in race relations to design a probing and personal questionnaire that would identify other previously overlooked but able candidates, and in doing so, increase the diversity of the incoming students, in an attempt to rebalance the racial and socioeconomic disparity. ${ }^{92}$ The initial results show a commendable $5 \%$ increase in the number of students with diverse attributes. In the US, the American Medical Colleges Experience-AttributesMetrics Model gives importance to life experiences a student has had before medical school or residency, in addition to their education, leadership, and community service. ${ }^{93}$ However, this model is not as explicitly supportive of students as the University of Manitoba system, which gives value to the many challenges of social deprivation.

\section{Limitations}

Certainly, the research on racism and racial bias, and its effect on cardiovascular health, has limitations. Bias can be expressed both directly and indirectly. In addition to the differences in the expression of bias, there are differences in the underlying process of bias (implicit vs explicit bias). Measurement of bias in medicine is presumed to be similar to that in the general population, but it is unclear if a specific test to assess bias in medicine is needed. Additionally, validity of any assessment of bias based on diverse races and ethnicities is needed, as the majority of the research to date has had an almost exclusive focus on Black populations. Implicit bias can also extend to persons with specific conditions, such as those with disabilities, mental illnesses, obesity, or substance abuse. The disparity is found in results of research examining the relationship between implicit bias and health outcomes.

\section{Conclusions}

Racism and racial bias on an individual and societal level negatively impacts the health of people of colour and Indigenous populations. The effects of racism and the social determinants of health are intertwined. Racism impairs mental and physical health and is the driver of poor cardiovascular health and outcomes in minority individuals. Global events in 2020, including the disparate impact of the COVID-19 pandemic on communities of colour and highly publicized incidents of police brutality fuelled by racism, have sparked an international movement to address and abolish racism. Policymakers, legal professionals, law enforcement officers, and medicine and healthcare professionals all have a role to play. We believe that the strongest "anti-racism statement" that those in the field of medicine can make is to diversify its ranks, and we stand with cardiologists and all physicians and healthcare workers who oppose racism and bias in their daily work.

\section{Acknowledgements}

Shrilla Banerjee and F. Aaysha Cader are recepients of the WomenAsOne Escalator Award 2021.

\section{Funding Sources}

The authors have no funding sources to declare.

\section{Disclosures}

The authors have no conflicts of interest to disclose.

\section{References}

1. Jones PC. Levels of racism: a theoretic framework and a gardener's tale. Am J Publ Health 2000;90:1212-5.

2. Nosek BA, Smyth FL, Hansen JJ, et al. Pervasiveness and correlates of implicit attitudes and stereotypes. Eur Rev Soc Psychol 2007;18:36-88.

3. Devine PG, Forscher PS, Austin AJ, Cox WTL. Long-term reduction in implicit race bias: a prejudice habit-breaking intervention. J Exp Soc Psychol 2012;48:1267-78.

4. Sinning C, Aržanauskaite M. Breaking the silence on bias: the expectations of being a physician. Eur Heart J Case Rep 2021;5. ytab256.

5. Greenwald AG, Banaji MR, Rudman LA, et al. A unified theory of implicit attitudes, stereotypes, self-esteem, and self-concept. Psychol Rev 2002;109:3-25.

6. Banaji MR, Greenwald AG. Blindspot: Hidden Biases of Good People. New York: Delacorte Press, 2013.

7. Churchwell K, Elkind MSV, Benjamin RM, et al. Call to action: structural racism as a fundamental driver of health disparities: a presidential advisory from the American Heart Association. Circulation 2020;142: e454-68.

8. Safford MM, Reshetnyak E, Sterling MR, et al. Number of social determinants of health and fatal and nonfatal incident coronary heart disease in the REGARDS study. Circulation 2021;143:244-53.

9. Razai MS, Kankam HKN, Majeed A, Esmail A, Williams DR. Mitigating ethnic disparities in covid-19 and beyond. BMJ 2021;372. m4921.

10. Phillips-Beck W, Eni R, Lavoie JG, et al. Confronting racism within the Canadian healthcare system: systemic exclusion of First Nations from quality and consistent care. Int J Environ Res Public Health 2020;17: 8343 .

11. Boynton-Jarrett R, Raj A, Inwards-Breland DJ. Structural integrity: recognizing, measuring, and addressing systemic racism and its health impacts. EClinicalMedicine 2021;36:100921.

12. Hahn RA, Truman BI, Williams DR. Civil rights as determinants of public health and racial and ethnic health equity: health care, education, employment, and housing in the United States. SSM Popul Health 2018;4:17-24.

13. MacPherson W. The Stephen Lawrence Inquiry. Report of an Inquiry. London, United Kingdom: The Stationary Office, 1999.

14. Aspinall PJ, Jacobsen B. Ethnic Disparities in Health and Health care: A Focused Review of the Evidence and Selected Examples of Good Practice: Executive Summary. London: London Health Observatory, 2004. 
15. Public Broadcasting Service (PBS) Newshour. In the UK, people of color are hit harder by COVID-19. Here's the story of 1 family's loss. Available at: https://www.pbs.org/newshour/show/in-the-uk-people-of-color-arehit-harder-by-covid-19-heres-the-story-of-1-familys-loss. Accessed June 28, 2021.

16. Public Health England. Disparities in the Risk and Outcomes of COVID19, 2020. Available at: https://assets.publishing.service.gov.uk/government/ uploads/system/uploads/attachment_data/file/908434/Disparities_in_the_ risk_and_outcomes_of_COVID_August_2020_update.pdf. Accessed June 28, 2021.

17. Centers for Disease Control and Prevention (CDC). Racism and Health | Health Equity | CDC. Health Equity. Available at: https://www.cdc.gov/ healthequity/racism-disparities/index.html. Accessed June 28, 2021.

18. Dolezsar CM, McGrath JJ, Herzig AJM, Miller SB. Perceived racial discrimination and hypertension: a comprehensive systematic review. Health Psychol 2014;33:20-34.

19. Britt-Spells AM, Slebodnik M, Sands LP, Rollock D. Effects of perceived discrimination on depressive symptoms among Black men residing in the United States: a meta-analysis. Am J Men's Health 2018;12:52-63.

20. Ayotte BJ, Hausmann LRM, Whittle J, Kressin NR. The relationship between perceived discrimination and coronary artery obstruction. Am Heart J 2012;163:677-83.

21. Duru OK, Harawa NT, Kermah D, Norris KC. Allostatic load burden and racial disparities in mortality. J Natl Med Assoc 2012;104:89-95.

22. Groeneveld PW, Kruse GB, Chen Z, Asch DA. Variation in cardiac procedure use and racial disparity among Veterans Affairs hospitals. Am Heart J 2007;153:320-7.

23. Albert MA, Ayanian JZ, Silbaugh TS, et al. Early results of Massachusetts healthcare reform on racial, ethnic, and socioeconomic disparities in cardiovascular care. Circulation 2014;129:2528-38.

24. Cram P, Bayman L, Popescu I, Vaughan-Sarrazin MS. Racial disparities in revascularization rates among patients with similar insurance coverage. J Natl Med Assoc 2009;101:1132-9.

25. The National Centre for Truth and Reconciliation Reports. Truth and Reconciliation Commission of Canada: Calls to Action. 2015. Available at: https://ehprnh2mwo3.exactdn.com/wp-content/uploads/2021/01/ Calls_to_Action_English2.pdf. Accesssed November 16, 2021.

26. Wang TY, Kaltenbach LA, Cannon CP, et al. Effect of medication copayment vouchers on P2Y12 inhibitor use and major adverse cardiovascular events among patients with myocardial infarction: the ARTEMIS randomized clinical trial. JAMA 2019;321:44-55.

27. Alsan M, Garrick O, Graziani G. Does diversity matter for health? Experimental evidence from Oakland. Am Econ Rev 2019;109: 4071-111.

28. Carriere G, Garner R, Sanmartin C. The health of First Nations living offreserve, Inuit, and Métis adults in Canada: the impact of socio-economic status on inequalities in health. Available at: https://www150.statcan.gc. ca/n1/en/catalogue/82-622-X2010004. Accessed June 28, 2021.

29. Tjepkema M, Wilkins R, Goedhuis N, Pennock J. Cardiovascular disease mortality among First Nations people in Canada, 1991-2001. Chronic Dis Inj Can 2012;32:200-7.

30. Chu A, Han L, Roifman I, et al. Trends in cardiovascular care and event rates among First Nations and other people with diabetes in Ontario, Canada, 1996-2015. CMAJ 2019;191:E1291-8.

31. Allen L, Hatala A, Ijaz S, Courchene ED, Bushie EB. Indigenous-led health care partnerships in Canada. CMAJ 2020;192:E208-16.
32. Reinier K, Nichols GA, Huertas-Vazquez A, et al. Distinctive clinical profile of Blacks versus Whites presenting with sudden cardiac arrest. Circulation 2015;132:380-7.

33. Reinier K, Thomas E, Andrusiek DL, et al. Socioeconomic status and incidence of sudden cardiac arrest. CMAJ 2011;183:1705-12.

34. Starks MA, Schmicker RH, Peterson ED, et al. Association of neighborhood demographics with out-of-hospital cardiac arrest treatment and outcomes: Where you live may matter. JAMACardiol 2017;2:1110-8.

35. Moon S, Bobrow BJ, Vadeboncoeur TF, et al. Disparities in bystander CPR provision and survival from out-of-hospital cardiac arrest according to neighborhood ethnicity. Am J Emerg Med 2014;32:1041-5.

36. Al-Khatib SM, Stevenson WG, Ackerman MJ, et al. 2017 AHA/ACC/ HRS guideline for management of patients with ventricular arrhythmias and the prevention of sudden cardiac death: executive summary. Circulation 2018;138:e210-71.

37. Giacomini MK. Gender and ethnic differences in hospital-based procedure utilization in California. Arch Intern Med 1996;156:1217-24.

38. Johnson AE, Adhikari S, Althouse AD, et al. Persistent sex disparities in implantable cardioverter-defibrillator therapy. Pacing Clin Electrophysiol 2018;41:1150-7.

39. Hernandez AF, Fonarow GC, Liang L, et al. Sex and racial differences in the use of implantable cardioverter-defibrillators among patients hospitalized with heart failure. JAMA 2007;298:1525-32.

40. Cook NL, Orav EJ, Liang CL, Guadagnoli E, Hicks LS. Racial and gender disparities in implantable cardioverter-defibrillator placement: Are they due to overuse or underuse? Med Care Res Rev 2011;68:226-46.

41. Breathett K, Yee E, Pool N, et al. Does race influence decision making for advanced heart failure therapies? J Am Heart Assoc 2019;8:e013592.

42. Cohen MG, Fonarow GC, Peterson ED, et al. Racial and ethnic differences in the treatment of acute myocardial infarction: findings from the Get With the Guidelines-Coronary Artery Disease program. Circulation 2010;121:2294-301.

43. Anstey DE, Li S, Thomas L, Wang TY, Wiviott SD. Race and sex differences in management and outcomes of patients after ST-elevation and non-ST-elevation myocardial infarct: results from the NCDR. Clin Cardiol 2016;39:585-95.

44. Doshi R, Shah J, Jauhar V, et al. Comparison of drug eluting stents (DESs) and bare metal stents (BMSs) with STEMI: Who received BMS in the era of 2nd generation DES? Heart Lung 2018;47:231-6.

45. Grines CL, Klein AJ, Bauser-Heaton H, et al. Racial and ethnic disparities in coronary, vascular, structural, and congenital heart disease. Catheter Cardiovasc Interv 2021;98:277-94.

46. Feder G, Crook AM, Magee P, et al. Ethnic differences in invasive management of coronary disease: prospective cohort study of patients undergoing angiography. BMJ 2002;324:511-6.

47. Sekhri N, Timmis A, Chen R, et al. Inequity of access to investigation and effect on clinical outcomes: prognostic study of coronary angiography for suspected stable angina pectoris. BMJ 2008;336:1058-61.

48. Rashid M, Timmis A, Kinnaird T, et al. Racial differences in management and outcomes of acute myocardial infarction during COVID-19 pandemic. Heart 2021;107:734-40.

49. Bortnick AE, Shahid M, Shitole SG, et al. Outcomes of ST-elevation myocardial infarction by age and sex in a low-income urban community: the Montefiore STEMI Registry. Clin Cardiol 2020;43:1100-9. 
50. Peterson ED, Shaw LK, DeLong ER, et al. Racial variation in the use of coronary-revascularization procedures - are the differences real? Do they matter? N Engl J Med 1997;336:480-6.

51. Conigliaro J, Whittle J, Good CB, et al. Understanding racial variation in the use of coronary revascularization procedures: the role of clinical factors. Arch Intern Med 2000;160:1329-35.

52. Popescu I, Vaughan-Sarrazin MS, Rosenthal GE. Differences in mortality and use of revascularization in Black and White patients with acute MI admitted to hospitals with and without revascularization services. JAMA 2007;297:2489-95.

53. Ibrahim SA, Whittle J, Bean-Mayberry B, et al. Racial/ethnic variations in physician recommendations for cardiac revascularization. Am J Publ Health 2003;93:1689-93.

54. Li S, Chen A, Mead K. Racial disparities in the use of cardiac revascularization: Does local hospital capacity matter? PLoS ONE 2013;8: e69855.

55. Regueiro CR, Gill N, Hart A, et al. Primary angioplasty in acute myocardial infarction: Does age or race matter? J Thromb Thrombolysis 2003;15:119-23.

56. King KM, Khan NA, Quan H. Ethnic variation in acute myocardial infarction presentation and access to care. Am J Cardiol 2009;103: 1368-73.

57. Wilson JB, Jackson LR, Ugowe FE, et al. Racial and ethnic differences in treatment and outcomes of severe aortic stenosis: a review. JACC Cardiovasc Interv 2020;13:149-56.

58. Alkhouli M, Holmes DR Jr, Carroll JD, et al. Racial disparities in the utilization and outcomes of TAVR: TVT Registry report. JACC Cardiovasc Interv 2019;12:936-48.

59. Cruz Rodriguez B, Acharya P, Salazar-Fields C, Horne A. Comparison of frequency of referral to cardiothoracic surgery for aortic valve disease in Blacks, Hispanics, and Whites. Am J Cardiol 2017;120:450-5.

60. Alkhouli M, Alqahtani F, Holmes DR, Berzingi C. Racial disparities in the utilization and outcomes of structural heart disease interventions in the United States. J Am Heart Assoc 2019;8. e012125.

61. Bob-Manuel T, Sharma A, Nanda A, et al. A review of racial disparities in transcatheter aortic valve replacement (TAVR): accessibility, referrals and implantation. Ann Transl Med 2018;6:10.

62. Greenwald AG, McGhee DE, Schwartz JL. Measuring individual differences in implicit cognition: the implicit association test. J Pers Soc Psychol 1998;74:1464-80.

63. Forscher PS, Lai CK, Axt JR, et al. A meta-analysis of procedures to change implicit measures. J Pers Soc Psychol 2019;117:522-59.

64. Hagiwara N, Kron FW, Scerbo MW, Watson GS. A call for grounding implicit bias training in clinical and translational frameworks. Lancet 2020;395:1457-60.

65. Harvard Business Review. Diversity policies rarely make companies fairer, and they feel threatening to white men. Harvard Business Review. Available at: https://hbr.org/2016/01/diversity-policies-dont-helpwomen-or-minorities-and-they-make-white-men-feel-threatened. Accessed June 19, 2021.

66. The problem with implicit bias training. Scientific American. Available at: https://www.scientificamerican.com/article/the-problem-withimplicit-bias-training/. Accessed November 16, 2021.

67. Brunel FF, Tietje BC, Greenwald AG. Is the implicit association test a valid and valuable measure of implicit consumer social cognition? J Consumer Psychology 2004;14:385-404.
68. Green AR, Carney DR, Pallin DJ, et al. Implicit bias among physicians and its prediction of thrombolysis decisions for Black and White patients. J GenIntern Med 2007;22:1231-8.

69. Penner LA, Dovidio JF, Gonzalez R, et al. The effects of oncologist implicit racial bias in racially discordant oncology interactions. J Clin Oncol 2016;34:2874-80.

70. Sabin JA, Nosek BA, Greenwald AG, Rivara FP. Physicians' implicit and explicit attitudes about race by MD race, ethnicity, and gender. J Health Care Poor Underserved 2009;20:896-913.

71. Girod S, Fassiotto M, Grewal D, et al. Reducing implicit gender leadership bias in academic medicine with an educational intervention. Acad Med 2016;91:1143-50.

72. Carnes M, Devine PG, Manwell LB, et al. The effect of an intervention to break the gender bias habit for faculty at one institution. Acad Med 2015;90:221-30.

73. Capers Q. 4th, Clinchot D, McDougle L, Greenwald AG. Implicit racial bias in medical school admissions. Acad Med 2017;92:365-9.

74. Devine PG, Forscher PS, Cox WTL, et al. A gender bias habit-breaking intervention led to increased hiring of female faculty in STEMM departments. J Exp Soc Psychol 2017;73:211-5.

75. Pettigrew TF, Tropp LR. A meta-analytic test of intergroup contact theory. J Pers Soc Psychol 2006;90:751-83.

76. Eberhardt JL, Dasgupta N, Banaszynski TL. Believing is seeing: the effects of racial labels and implicit beliefs on face perception. Pers Soc Psychol Bull 2003;29:360-70.

77. Capers Q. How clinicians and educators can mitigate implicit bias in patient care and candidate selection in medical education. ATS Sch $2020 ; 1: 211-7$

78. Khatri U, Zeidan A, LaRiviere M, et al. An evaluation of implicit bias training in graduate medical education. MedEdPublish:8. Available at, https://www.mededpublish.org/manuscripts/2399. Accessed June 5, 2021.

79. Cirillo D, Catuara-Solarz S, Morey C, et al. Sex and gender differences and biases in artificial intelligence for biomedicine and healthcare. NPJ Digit Med 2020;3:81

80. Huded CP, Johnson M, Kravitz K, et al. 4-step protocol for disparities in STEMI care and outcomes in women. J Am Coll Cardiol 2018;71:2122-32.

81. Tat E, Bhatt DL, Rabbat MG. Addressing bias: artificial intelligence in cardiovascular medicine. Lancet Digit Health 2020;2:e635-6.

82. Francis DV, de Oliveira ACM, Dimmitt C. Do school counselors exhibit bias in recommending students for advanced coursework? BE J Econ Anal Pol 2021;19:1-17.

83. Fadus MC, Valadez EA, Bryant BE, et al. Racial disparities in elementary school disciplinary actions: findings from the ABCD Study. J AmAcad Child Adolesc Psychiatry 2021;60:998-1009.

84. Capers Q. 4th, Johnson A, Berlacher K, Douglas PS. The urgent and ongoing need for diversity, inclusion, and equity in the cardiology workforce in the United States. J Am Heart Assoc 2021;10:e018893.

85. Marrast LM, Zallman L, Woolhandler S, Bor DH, McCormick D. Minority physicians' role in the care of underserved patients. JAMA Intern Med 2014;174:289-91.

86. Saha S, Beach MC. Impact of physician race on patient decision-making and ratings of physicians: a randomized experiment using video vignettes. J GenIntern Med 2020;35:1084-91. 
87. Davila E. No more silence: confronting racism in medicine. Available at: https://blogs.bcm.edu/2020/06/19/no-more-silence-confronting-racismin-medicine/. Accessed June 28, 2021.

88. Dhara A. Our complicit role in systemic racism. Can Fam Phys 2020;66: 596-7.

89. Perritt J. \#WhiteCoatsForBlackLives—addressing physicians' complicity in criminalizing communities. N Engl J Med 2020;383:1804-6.

90. Potter J. Failure to challenge discriminatory behaviour is complicity. BMJ 2020;368. m147.
91. Johnson AE, Talabi MB, Bonifacino E, Culyba AJ, Davis EM. Racial diversity among American cardiologists: implications for the past, present, and future. Circulation 2021;143:2395-405.

92. Friesen J. In a push for diversity, medical schools overhaul how they select Canada's future doctors. The Globe and Mail. Availabel at: https://www.theglobeandmail.com/canada/article-in-a-push-fordiversity-medical-schools-overhaul-how-they-select/. Accessed June 28, 2021. 